\title{
Challenges and Implications Associated with Septic Abortion in India: A Review
}

\author{
Dr. Saeeda Wasim ${ }^{1}$, Tanish Baqar ${ }^{2 *}$, Dr. Shriya Arora ${ }^{3}$, Dr. Sharique Ahmad ${ }^{4}$ \\ ${ }^{1}$ Consultant, Nova IVF, Hazratganj, Lucknow, Uttar Pradesh, India \\ ${ }^{2}$ Undergraduate Student, Era's Lucknow Medical College and Hospital, Lucknow, Uttar Pradesh, India \\ ${ }^{2}$ Junior Resident, Department of Pathology, Era's Lucknow Medical College and Hospital, Lucknow, Uttar Pradesh, India \\ ${ }^{4}$ Department of Pathology, Era's Lucknow Medical College and Hospital, Lucknow, Uttar Pradesh, India
}

\begin{tabular}{ll}
\hline DOI: $10.36348 /$ sijog.2020.v03i09.002 & | Received: 24.08 .2020 | Accepted: 01.09 .2020 | Published: 03.09 .2020
\end{tabular}

*Corresponding author: Tanish Baqar

\section{Abstract}

With a population threatening towards 133.92 crores it is important for a country like India, to make mandatory efforts, providing health benefits to all especially those who are devoid till date. A terrific amount of strain is now being placed on the available medical facilities due to the low doctor-population ratio in India, which limits the time available for doctors to communicate with patients, especially those who belong to a lower socio economic class. Thousands of deaths are reported from unsafe abortion due to the lack of trained abortion providers, lack of knowledge, availability of safe services, compounded by the social stigma surrounding abortion. To save themselves from the surrounding stigma, they then turn towards local, less experienced doctors who charge low but, due to the lack of experience and proper knowledge the condition becomes more severe causing Septic abortion. Septic abortion, whether induced or spontaneously occurs because of improper, unsafe, and inadequate removal of products of conception. Subsequently products of conception become infected, bacteria infiltrate the placental tissue and infection spreads to the uterus. A condition unequivocally related to maternal complications such as hemorrhage, trauma and sepsis. Thus to avoid such outcomes the current article attempts to focus on the major challenges faced by the woman in India, further mentioning the prevention required and solutions associated with septic abortion.

Keywords: Septic Abortion; Contraception; Pregnancy; MTP-Act; Maternal mortality.

Copyright @ 2020: This is an open-access article distributed under the terms of the Creative Commons Attribution license which permits unrestricted use, distribution, and reproduction in any medium for non-commercial use (NonCommercial, or CC-BY-NC) provided the original author and source are credited.

\section{INTRODUCTION}

Septic abortion a condition causing serious medical emergency where abortion is associated with septic shock coupled with bilateral cortical necrosis and infection observed after a miscarriage or intentional termination of pregnancy [1]. Due to unsafe abortionrelated causes approx. 13 women die in India every day [2]. Unsafe abortion is the third driving clarification of maternal deaths in the nation; annually contributing eight percent of all such deaths [3].Unsafe abortion according to World Health Organization is for terminating unintended pregnancy by unskilled individuals or without proper medical standards or both. Thousands of deaths are pronounced from dangerous abortions due to a scarcity of skilled abortion providers, deficiency of consciousness for legality of abortion and the availability of secure services, compounded with the aid of the social stigma surrounding abortion [4].

Research indicates that more than $80 \%$ of the women are unaware that abortion is legal in India even at the $24^{\text {th }}$ week of pregnancy and this leads to women seeking terminations from Backstreet providers. [5]About $13 \%$ of all maternal deaths, the WHO estimates that 80,000 deaths from unsafe abortion occur in the world each year, frequently seen in underdeveloped countries [6]. WHO running paper summarizing the world literature after 1960, it lists nearly 400 published reports of abortion morbidity and mortality and concludes that "The greatest neglected problem being unsafe abortion practice in developing countries [7]'. Septic abortion, an infectious condition coupled by fever, parametritis and endometritis 
continues to be one of the foremost basic threats to women's wellbeing around the world [8]. Morbidity and mortality occurring from septic abortion are frequently observed in places like India which are still developing, where abortion is inaccessible to the majority and if accessible it is usually done in a manner causing post abortion complications [9-11].

A septic abortion will have equal suggestive clinical manifestations as an aseptic one, with the addition of the findings relating to an infective process [12]. At instances this infective process may additionally arrest or modify the symptoms which we consider it to be the characteristic phenomena of abortion [9]. Symptoms and signs that are related to abortion can be pelvic/abdominal pain, fever, uterine tenderness, vaginal bleeding, uterine tenderness, foul smelling vaginal discharge. Risk of loss of life from post abortion sepsis is more common for younger women and unmarried women, and it is more expected when the uterine content not directly evacuated [13]. With more superior gestations, the threat of perforation and retained tissue increases [10]. Delay in treatment leads to the progression of bacteremia, septic pelvic thrombophlebitis, DIC, shock, pelvic abscess, renal failure and loss of life [14].

In such a society where a girl-child is killed much before she is born and if by chance the abortion fails she is buried alive, thus preventing unwanted pregnancies and abortions is really difficult! And when this situation is coupled up with low income rates and a majority which lies below middle class, the patient prefers uneducated, ill experienced doctors as they charge less making it a situation simply life threatening[15].

\section{THE ACTS}

The PCPNDT Act (Pre-Conception and PreNatal Diagnostic Techniques) enforced in 1994 made sex-determination illegal, the root cause for the enforcement of this law was to prevent female infanticide [16]. While efforts to amend the MTP act are underway, Gynecologists say the amendment to allow termination till the 24th week of pregnancy, from the present 20th week, helps terminate and detect anomalies in the developing fetus [17]. Some anomalies evolve and can be detected only after the 18th week; test results take a couple of weeks more. By then, in many cases, a woman would have crossed her 20th week of pregnancy; barring her from going ahead with MTP thus the proposed amendment is a boon for such people [18]. During a scan, it's devastating for a family to learn, nothing can be done to terminate the pregnancy at this stage. In such cases the current MTPAct provides a legal window to terminate pregnancy till the $24^{\text {th }}$ week, which will help a lot of women in need [19]. In India, which is a country with immense social baggage supplemented by societal evils such as illiteracy and poverty, the impact of the MTP Act attempts to translate into reality for the majority of Indian women, particularly those belonging to the lower socio economic class [15].

\section{Challenges for septic abortion in India Challenge 1: Attitude towards women}

Stigma and attitude towards female specifically young, single, underprivileged women searching for abortion additionally make a contribution to the variety of abortions, some companies refuse to operate abortions on young ladies who are poor or demand that they carry their guardians to the health center. It has also emerged that women who had experienced abortion earlier constantly perceive their health status as relatively worse than their counterparts [20-21].

\section{Challenge 2: Problems faced by the Rural Sector}

In rural India, most of the women are unaware, unprivileged, they lack sex education and those who do prefer opting for pills to avoid being shamed in a hospital by insensitive government hospital nurses and doctors who play up the stigma surrounding abortion.

1. Trained medical practitioner are not available like increased trained professionals in abortion techniques will also bolster the provide skill needed.

2. Limited understanding of legality of abortion.

3. Lack of awareness for seeking abortion early in pregnancy.

4. Poor care in government hospitals.

\section{Challenge 3: Consent}

While the regulation requires the consent of solely the female if she is over the age of 18 years, in practice, many providers additionally ask for consent from the partner or some other relative thus forcing many women to practice unsafe abortion ladies to flip to clandestine and dangerous abortion methods [22]. Since risks from pregnancy to younger girls are much higher since the body is very small, can lead to death or other severe complications like shock peritonitis.

\section{Challenge 4: Unregistered private abortion service providers}

Abortions without proper healthcare or sanitary conditions can be fatal. If it is performed by unqualified personnel and/or in unhygienic conditions, unsafe abortions can cause life-threatening complications including severe bleeding, infections and peritonitis. Women consult these unqualified professionals because of greater confidentiality and less judgment [23].

\section{Challenge 5: Charging Extra money from Low socio-economic class}

Reports have mentioned how neglected, pregnant women in rural India were compelled to pay for deliveries and post-delivery services at supposedly 
free public health centers [24] forcing many others to try unsafe self-abortion leading to sepsis.

\section{Challenge 8: Accessibility of the MTP Act}

If you look at accessibility, the MTP Act defines who can provide legal and safe abortion services and the place where it can be provided. [25] MTP act clearly defines who can seek an abortion and the law permits abortion for both married and unmarried females. Due to social obligations unmarried females are not given the same option leading to following of incorrect procedures like pills which cause an incomplete abortion and septic abortions.

\section{Challenge 7: Desire for a Male Child}

Son-preference in Indian cultures is largely based on the fact that men are better providers, they provide security for the elderly and that sons are required for the performance of funeral rites thus female infanticide became a significant problem in rural areas of India leading to a prior abortion at any cost.

\section{Challenge 6: Lack of proper Access}

Millions of women become pregnant because they lack access to contraceptive devices to limit or space their families, or are fearful of using them, or are ignorant about the contraceptive devices [24]. More than 10 million women terminate their pregnancies in the privacy of their homes, reflecting the government's failure to adequately address family planning needs, endangering mothers and keeping India more populated than it might be if women had access to and knowledge of contraceptives [26].

\section{Challenge 9: Lack of skilled providers}

Despite the liberal legislation Medical Termination of Pregnancy Act (MTP Act) that governs abortions in India, non-availability of skilled providers, and distinct documentation coupled with terrible perception about the legality of abortions make contributions to abortion associated deaths [27].

\section{Challenge 10: Lack of Awareness and Negligent Attitude}

Underprivileged, younger and single female is greater in all likelihood to lengthen abortion due to the fact that they are frequently poorly knowledgeable on many fronts: they might also now not apprehend the symptoms of pregnancy, opportunity or legality of acquiring the abortion and the area of protected services [28].

\section{Challenge 11: Medical Quackery}

While traditional and psychological taboos still inherent in most Indian women, they continue to keep quacks and illegal abortionists in business. It is believed that the majority of Indian women looking to undergo abortions do so by self-medication or through quacks owing to the stigma and lack of awareness surrounding such procedures. They approach either the elder women in their family or quacks in the neighborhood. Abortion without medical supervision can result in ectopic pregnancies and the results are life-threatening.

\section{Challenge 12: Fear of tedious Legal Procedures}

To avoid getting involved in legal proceedings, doctors refuse to treat and perform abortions on minors. Fearing persecution under the POCSO Act, doctors' subject women to extra-legal procedures such as filing affidavits, which have no basis in the Act itself before they perform the abortion because of this, victims of sexual violence, who are already involved in criminal proceedings, are reluctant to report their pregnancy and indulging themselves in self-assisted abortion methods.

\section{Challenge 13:Diagnostic facility unavailability}

Diagnostic facility includes both Diagnostic imaging and microbiological services. Diagnostic imaging helps to detect retained products of conception, perforation in the uterus and spread of infection to other parts like peritoneum. Scanning on Ultrasound helps in the visualization of dilated tubes, tubo-ovarian abscess and collection of exudates in the peritoneal cavity, lack in these modalities leads to the misdiagnosis of septic abortion. Microbiological studies related to blood, endocervical and evacuated specimen helps in identifying involved bacteria. Isolated organism usually includes bacteria, such as peptostreptococcus, staphylococcus aureus, Clostridium perfringens, E.coli and many others.

\section{Challenge 14: Lack of awareness about sexually transmitted diseases}

Many people are unaware about sexually transmitted diseases and tend to ignore them. The presence of sexually transmitted diseases with organism such as Chlamydia Trachomatis and Nisseria Gonorrhoea established a risk factor for septic abortion. Proper treatment should be given against these diseases.

\section{Challenge 15: Lack of proper sterilization of instruments}

Due to untrained professionals or ignorance the use of improper or unsterilized instruments leads to septic abortion. Inadequate knowledge about the sterilization process, especially in rural areas is one of the causes. Various reasons could be

a. Lack or inadequate knowledge about sterilization process

b. Non availability of resources required for sterilization

c. Careless behavior of Medical professionals

d. Even in urban areas carelessness and nonavailability can lead to improper sterilization practices.

\section{Challenge 16: Incomplete coverage of antibiotics}

Females undergoing surgical procedures for abortion (D\&C /D\&E) lead to introduction of surgical instruments to prevent any sepsis from their proper 
coverage of antibiotics before and after treatment are essential. Instrumentation can lead to the introduction of various organisms which can alter the normal vaginal flora. If it becomes pathogenic can cause pelvic infections and can present with systemic symptoms. This causes single antibiotic therapy to become ineffective. To fight against this polymicrobial nature of organism involved combination therapy is mostly preferred.

a. Availability of antibiotics

b. Appropriate compliance of patients for combination therapy antibiotics

c. Protocol and knowledge about antibiotics to be followed

\section{PREVENTION}

Primary prevention consists of [29]

- Contraception which is acceptable and cost effective.

- In case of contraceptive failure right of entry to legal, safe abortion.

- Averting unintended pregnancies.

- Suitable clinical administration of abortion.

\section{Secondary prevention requires}

- Early detection and treatment of the conundrum.

- Halting the ailment procedure should be the aim.

- Instantaneous analysis and advantageous reme dy of endometritis to keep away from more serious infections.[30]

\section{Tertiary prevention seeks to}

- Minimizes the damage carried out by means of disorder and avoids incapacity [30].

- To prevent serious consequences of infection.

- Hospitalization for parenteral antibiotic remedy and immediate uterine evacuation for any patient with severe complaint.[29]

- Proper management is necessary in case of extreme sepsis, involving pelvic peritonitis and raised body temperature.

- Eradication of the contamination and supportive care for different concerned organ systems.

- Clinical improvement is seen by absence of fever, vaginal discharge, pelvic pain or improvement in ultrasound findings such as reduction in size of tubo-ovarian mass.

\section{SOLUTIONS}

Despite a relatively liberal and longstanding MTP law that governs abortion in India, women continue to suffer the dire consequences of unsafe procedures owing to poor quality of services and the stigma surrounding the issue. [31] While they lack the freedom to plan pregnancies, they also face multiple barriers when they seek abortions. The barriers include poor knowledge about safe abortion services and laws, and socio-cultural norms that render abortions taboo and lead to terrible bias among service providers [31]. To overcome this we need to strengthen safe abortion services as well as enable open conversation so as to banish bias.

It is obligatory for a health care provider to supply lifesaving clinical care to any woman who suffers abortion associated complications regardless of the legal grounds for abortion [32]. A greater focus on spacing and limiting methods by making more contraception options available would help avoid unwanted pregnancies in the first place and reduce reliance on abortion pills which is difficult for rural women to correlate [32]. The exercise of extracting confessions from girl in search of emergency clinical care as an end result of unlawful abortion places women's life at risk. The legal requirement for medical practitioners and different health care personnel to file instances of ladies who have gone through abortion, delays care and will increase the hazard to women's health care and lives [31]. When we talk about decreasing maternal mortality caused by septic abortion, it is not primarily about improving quality of services around labor and delivery in the public and private sectors [33]. It is also about the quality of primary healthcare, apart from the quality of services like abortion, D\&C (dilation and curettage procedure) and all those procedures [33]. Minimal rules should be there before allowing someone for an abortion. Consent of a woman should be more than enough.

\section{CONCLUSION}

Death and serious problems from abortionrelated contamination is completely avoidable [34]. A prerequisite to stopping undesirable pregnancy in all countries is social equality: to let the women in your society choose what they feel is right under government guidelines and to have proper access of various contraceptive methods which they consider secure and cost effective without the consent of our patriarchal society [35]. Sex education frequently fails to inform about contraception due to the facts associated with inaccurate concepts that such training about contraception encourages sexual experimentation [35]. In fact, teenagers coming to family planning clinics are commonly sexually active long before seeking the services. Education about biology is no longer enough [36]. Actual services need to be supplied that are easily available and inexpensive. Proper education about sex, abortion, contraception and individual rights should be provided in schools itself. We are obligated to put health first, to do so by means of respecting the highestquality, accessible scientific evidence, to all women, including not just urban sector, but rural as well, by erasing the religious or economic barriers and providing safe and cost effective benefits to all [37]. The consequences of unsafe abortion, women's health and 
well-being should to be recounted by all of us in the society and intensive dissemination of statistics and commitments at all degrees are required.

\section{REFERENCE}

1. Stubblefield, P. G., \& Grimes, D. A. (1994). Septic abortion. New England Journal of Medicine, 331(5), 310-314.

2. Rotheram Jr, E. B., \& Schick, S. F. (1969). Nonclostridial anaerobic bacteria in septic abortion. The American journal of medicine, 46(1), 80-89.

3. Studdiford, W. E., \& Douglas, G. W. (1956). Placental bacteremia: a significant finding in septic abortion accompanied by vascular collapse. American journal of obstetrics and gynecology, 71(4), 842-858.

4. Rana, A., Pradhan, N., Gurung, G., \& Singh, M. (2004). Induced septic abortion: a major factor in maternal mortality and morbidity. Journal of Obstetrics and Gynaecology Research, 30(1), 3-8.

5. Grimes, D. A., Cates, J. W., \& Selik, R. M. (1981). Fatal septic abortion in the United States, 19751977. Obstetrics and gynecology, 57(6), 739-744.

6. Stewart, G. K., \& GOLDSTEIN, P. J. (1971). Effects on Septic Abortion and Maternal Mortality. Obstetrics \& Gynecology,37(4), 510514.

7. Finkielman, J. D., De Feo, F. D., Heller, P. G., \& Afessa, B. (2004). The clinical course of patients with septic abortion admitted to an intensive care unit. Intensive care medicine, 30(6), 1097-1102.

8. Neuwirth, R. S., \& Friedman, E. A. (1963). Septic abortion. Changing concept of management. Obstetrical \& Gynecological Survey, 18(3), 380-382.

9. Smith, J. W., Southern, P. M., \& Lehmann, J. D. (1970). Bacteremia in septic abortion: complications and treatment. Obstetrics \& Gynecology, 35(5), 704-708.

10. Seward, P. N., Ballard, C. A., \& Ulene, A. L. (1973). The effect of legal abortion on the rate of septic abortion at a large county hospital. American journal of obstetrics and gynecology, 115(3), 335338.

11. Aslam, A. F., Aslam, A. K., Thakur, A. C., Vasavada, B. C., \& Khan, I. A. (2005). Staphylococcus aureus infective endocarditis and septic pulmonary embolism after septic abortion. International journal of cardiology, 105(2), 233-235.

12. Konje, J. C., Obisesan, K. A., \& Ladipo, O. A. (1992). Health and economic consequences of septic induced abortion. International Journal of Gynecology \& Obstetrics, 37(3), 193-197.

13. Sreelakshmi, U., Thejaswini, J., \& Bharathi, T. (2014). The outcome of septic abortion: a tertiary care hospital experience. The Journal of Obstetrics and Gynecology of India, 64(4), 265-269.
14. Giri, A., Srivastav, V. R., Suwal, A., \& Sharma, B. (2015). A study of complications following selfadministration with medical abortion pills. Nepal Journal of Obstetrics and Gynaecology, 10(1), 2024.

15. Chatterjee, C., Joardar, G. K., Mukherjee, G., \& Chakraborty, M. (2006). Septic abortions: a descriptive study in a teaching hospital at North Bengal, Darjeeling. In Editorial Board Vol. 51 No. 3 July-September 2007 Conference Issue (Vol. 51, No. 3).

16. Potdar, P., Barua, A., Dalvie, S., \& Pawar, A. (2015). "If a woman has even one daughter, I refuse to perform the abortion": Sex determination and safe abortion in India. Reproductive health matters, 23(45), 114-125.

17. Lemoine, K., \& Tanagho, J. (2007). Gender Discrimination Fuels Sex Selective Abortion: The Impact of the Indian Supreme Court on the Implementation and Enforcement of the PNDT Act. U. Miami Int'l \& Comp. L. Rev., 15, 203.

18. Duggal, R., \& Ramachandran, V. (2004). The abortion assessment project-India: key findings and recommendations. Reproductive health matters, 12(sup24), 122-129.

19. Nandi, A., \& Deolalikar, A. B. (2013). Does a legal ban on sex-selective abortions improve child sex ratios? Evidence from a policy change in India. Journal of Development Economics, 103, 216-228.

20. Duggal, R., \& Ramachandran, V. (2004). The abortion assessment project-India: key findings and recommendations. Reproductive health matters, 12(sup24), 122-129.

21. Mundle, S., Elul, B., Anand, A., Kalyanwala, S., \& Ughade, S. (2007). Increasing access to safe abortion services in rural India: experiences with medical abortion in a primary health center. Contraception, 76(1), 66-70.

22. Duggal, R. (2004). The political economy of abortion in India: cost and expenditure patterns. Reproductive Health Matters, 12(sup24), 130-137.

23. Yadav, B, Batra, A., Gautam, S. (2015). Selfinduced medical abortion: a rising challenge. Journal of evolution of medical and dental sciences, 4(79):13895-13903.

24. Banerjee B. Comments to: Induced Abortion and Traumatic Stress: A Preliminary Comparison of American and Russian Women. Medical Science Monitor. 2007 Sep 1; 13(9):LE11-2.

25. Thaker, R. V., Deliwala, K. J., \& Shah, P. T. (2014). Self-Medication of Abortion Pill: Women's Health in Jeopardy. NHL Journal of Medical Sciences, 3(1).

26. Guin, G., Gupta, A., Khare, S., Chandra, M., \& Kalkar, S. (2005). A study of septic abortions: trends in a tertiary hospital. J Obstet Gynecol Ind, 55(3), 257-260. 
27. Nivedita, K., \& Shanthini, F. (2015). Is it safe to provide abortion pills over the counter? A study on outcome following self-medication with abortion pills. Journal of clinical and diagnostic research: JCDR, 9(1), QC01.

28. Banerjee, S. K., Andersen, K. L., \& Warvadekar, J. (2012). Pathways and consequences of unsafe abortion: a comparison among women with complications after induced and spontaneous abortions in Madhya Pradesh, India. International Journal of Gynecology \& Obstetrics, 118, S113S120.

29. Peña, E.F. (1954). Prevention of abortion. The American Journal of Surgery. 1954 Jan 1; 87(1):95-96.

30. Achilles, S.L., Reeves, M.F. (2011). Prevention of infection after induced abortion. Contraception, 1; 83(4):295-309.

31. World Health Organization. (1993). The Prevention and management of unsafe abortion: report of a technical working group, Geneva, 1215 April 1992 (No. WHO/MSM/92.5. Unpublished). World Health Organization.

32. Arora, N., \& Mittal, S. (2005). Emergency contraception and prevention of induced abortion in India. BMJ Sexual \& Reproductive Health, 31(4), 294-296.
33. Sri, B. S., \& Ravindran, T. S. (2012). Medical abortion: understanding perspectives of rural and marginalized women from rural South India. International Journal of Gynecology \& Obstetrics, 118, S33-S39.

34. Hertog, E., \& Iwasawa, M. (2011). Marriage, abortion, or unwed motherhood? How women evaluate alternative solutions to premarital pregnancies in Japan and the United States. Journal of Family Issues, 32(12), 1674-1699.

35. Ravindran, T. S. (2015). Safe, accessible medical abortion in a rural Tamil Nadu clinic, India, but what about sexual and reproductive rights?. Reproductive health matters, 22(44), 134143.

36. Singh, S., Shekhar, C., Acharya, R., Moore, A. M., Stillman, M., Pradhan, M. R., \& Sundaram, A. (2018). The incidence of abortion and unintended pregnancy in India, 2015. The Lancet Global Health, 6(1), e111-e120.

37. Lakha, F., \& Glasier, A. (2006). Unintended pregnancy and use of emergency contraception among a large cohort of women attending for antenatal care or abortion in Scotland. The Lancet, 368(9549), 1782-1787. 